\title{
Power Interruption Costs to Commercial Customers of Electricity in Korea
}

\author{
Dong-Sub Kim* and Kil-Sin Kim ${ }^{\dagger}$
}

\begin{abstract}
This paper presents the result of the estimation of the power interruption costs of Korean commercial customers. Commercial customers are usually located in urban areas and considered very important because a power interruption on them can expand to additional damage to related users. Their power interruption costs were calculated through a survey with the process of data selection. Also, the power interruption cost for each customer's business type was calculated and compared with that of foreign cases.
\end{abstract}

Keywords: Interruption cost, Customer survey, Commercial customer, Microscopic method, KSIC

\section{Introduction}

Although more investment is needed to improve the reliability of power supply, it doesn't always bring benefits to customers in every way. Increase in the investment is accompanied by increase of the tariff and finally ends up with more burden on customers. So it is very difficult for utilities to decide how high the reliability should be set because it is not sure how much the decided reliability level would affect customers [1,2].

Power interruption cost means the customers' loss related with a power interruption or the social cost when $100 \%$ of reliability cannot be expected. Power interruption includes not only power outages but also all the situations in which customers cannot maintain their normal livings due to power related problems such as low frequency. And power interruption cost means customers' direct and indirect loss from it including costs to prevent power interruption. Costs from the sudden power interruption and aftermath that makes the normal productive life impossible are called direct cost. Indirect cost means the cost customers pay to alleviate the damage from the expected power interruption. In a recent survey, it says the average power interruption cost of a data center in the U.S is $\$ 627,418$ in which direct cost takes $40 \%$, indirect cost takes $49 \%$, and loss of opportunity takes the rest of $11 \%$ [3].

There are macroscopic and microscopic methods to estimate the power interruption cost. Though the macroscopic method, in which the national GDP is divided by the entire power consumption, has its own merits in estimating the power interruption cost easily, it has some problems in evaluating the power reliability with inaccurate consideration of components such as customer type, weather, time and duration of power interruption, etc.

$\dagger$ Corresponding Author: Distribution Laboratory, Korea Electric Power Research Institute(KEPRI), Korea. (iamhappy@kepco.co.kr)

* School of Technology Policy, Yonsei University, Korea. (kimdons@, kepco.co.kr)

Received: March 18, 2013; Accepted: April 16, 2014
To the contrary, in the microscopic method, customers are asked to estimate their costs or losses due to supply outages of varying duration and frequency. The strength of this method lies in the fact that the customer is probably in the best position to assess the losses. Direct costs are relatively easy to determine for some customer categories (e.g., industrial), but users' opinions are particularly important in assessing less tangible losses, such as inconvenience, for other categories (e.g., residential). Another advantage is that the method can readily be tailored to seek particular information as related to the specific needs of the utility. Obviously, this method is beset with all the problems of questionnaire surveys, and the cost and effort of undertaking surveys is significantly higher than using other approaches outlined earlier. Nevertheless, this approach appears to be the method favored by utilities which require interruption cost data for planning purposes [4].

In this paper, the power interruption cost of the Korean commercial customer is estimated with a microscopic method. Usually, commercial customers are considered very important ones because they are located in center of cities and the power interruption to them can bring additional damage to their own customers. To represent the average Korean commercial customer, samples were evenly chosen from all over the country. Also well-trained surveyors were put to secure high reliability of the survey result.

\section{Customer survey approach}

\subsection{Method used in survey}

This survey had been done in a nation-wide scale in September and October in 2013 with 738 commercial customers. As of 2013, there are about 1,830 thousand of commercial customers in Korea and they take $13.6 \%$ of the power sold. Table 1 shows the types of business areas commercial customers are involved in based on KSIC 
Table 1. Type of Business(KSIC)

\begin{tabular}{|c|c|c|}
\hline Category & & Types \\
\hline \multirow{3}{*}{$\begin{array}{l}\text { Wholesale } \\
\text { and retail } \\
\text { trade }\end{array}$} & 1 & Sale of motor vehicles and parts \\
\hline & 2 & $\begin{array}{l}\text { Wholesale trade and commission trade, } \\
\text { except of motor vehicles and motorcycles }\end{array}$ \\
\hline & 3 & $\begin{array}{l}\text { Retail trade, except motor vehicles and } \\
\text { motorcycles }\end{array}$ \\
\hline \multirow{4}{*}{ Transportation } & 4 & Land transport; transport via pipelines \\
\hline & 5 & Water transport \\
\hline & 6 & Air transport \\
\hline & 7 & $\begin{array}{l}\text { Storage and support activities for } \\
\text { transportation }\end{array}$ \\
\hline \multirow{2}{*}{$\begin{array}{l}\text { Accommodation and } \\
\text { food service activities }\end{array}$} & 8 & Accommodation \\
\hline & 9 & Food and beverage service activities \\
\hline \multirow{6}{*}{$\begin{array}{l}\text { Information and } \\
\text { communications }\end{array}$} & 10 & Publishing activities \\
\hline & 11 & $\begin{array}{l}\text { Motion picture, video and television } \\
\text { programme production, sound recording } \\
\text { and music publishing activities }\end{array}$ \\
\hline & 12 & Broadcasting \\
\hline & 13 & Telecommunications \\
\hline & 14 & $\begin{array}{l}\text { Computer programming, consultancy and } \\
\text { related activities }\end{array}$ \\
\hline & 15 & Information service activities \\
\hline \multirow{2}{*}{$\begin{array}{c}\text { Human health and } \\
\text { social work activities }\end{array}$} & 16 & Human health \\
\hline & 17 & Social work activities \\
\hline \multirow{2}{*}{$\begin{array}{l}\text { Arts, sports and } \\
\text { recreation related } \\
\text { services }\end{array}$} & 18 & $\begin{array}{l}\text { Creative, arts and recreation related } \\
\text { services }\end{array}$ \\
\hline & 19 & Sports activities and amusement activities \\
\hline \multirow{2}{*}{$\begin{array}{l}\text { Repair and other } \\
\text { personal services }\end{array}$} & 20 & Maintenance and repair services \\
\hline & 21 & Other personal services activities \\
\hline
\end{tabular}

Table 2. Survey contents

\begin{tabular}{c|l}
\hline Contents & \multicolumn{1}{|c}{ Details } \\
\hline Basic information & Area, Address, Employees, Work hours \\
\hline Business types & 7 categories, 21 types \\
\hline Electrical details & $\begin{array}{l}\text { Contract / peak power, Consumption, Tariff, } \\
\text { Emergency back-ups }\end{array}$ \\
\hline Power qualities & $\begin{array}{l}\text { Swell, Sag, Overvoltage, Undervoltage, Momentary, } \\
\text { Temporary, Sustained }\end{array}$ \\
\hline Max. duration & Seasonal, Daily, Hourly \\
\hline
\end{tabular}

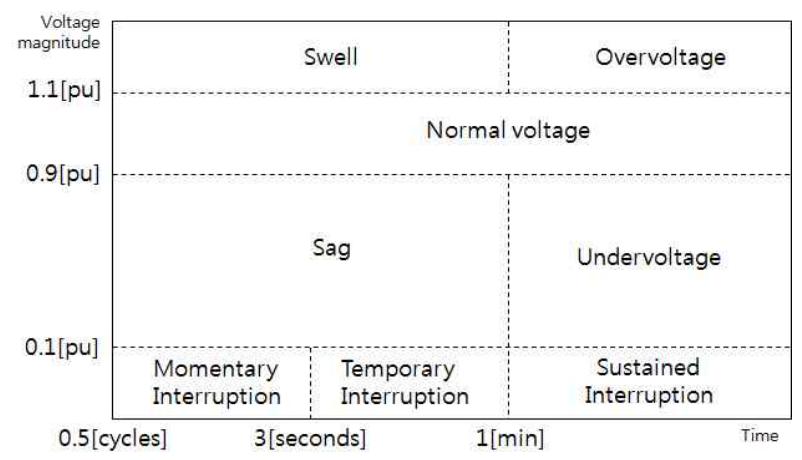

Fig. 1. Power quality classification

(Korean Standard Industrial Classification).

The questionnaire used in the survey was appropriately modified from that ones developed and used by the EPRI and KEPCO [5]. Table 2 shows main contents of the questionnaire. To calculate the power interruption cost for each type, commercial customers were classified in 21 types and their power consumption, power qualities, and
Table 3. Survey contents of damage cost and interruption duration

\begin{tabular}{c|c|c|c}
\hline \multicolumn{2}{|c|}{ Damage category } & \multicolumn{2}{|c}{ Interruption duration } \\
\hline 1 & $\begin{array}{c}\text { Labor cost paid } \\
\text { for business loss }\end{array}$ & 1 & 1 minute \\
\hline 2 & Business loss & 2 & 2 minutes \\
\hline 3 & Cost for extra work & 3 & 1 hour \\
\hline 4 & Damages to devices/materials & 4 & 2 hours \\
\hline 5 & Cost for shop reopening & 5 & 4 hours \\
\hline 6 & Cost for rotten products & 6 & 8 hours \\
\hline 7 & Emergency back-up cost & & \\
\hline 8 & Others & & \\
\hline
\end{tabular}

related damages were investigated. Among survey contents, daily and hourly power consumptions were answered with percentage for customers' convenience. Damages from the duration of power interruption excluding the worst time zone were also answered with the proportion compared to that from the worst time zone.

Power qualities were classified according to the international standard as shown in Fig. 1.

In the survey, damages of commercial customers were classified in 8 categories and the power interruption duration were classified as 1 minute, 20 minutes, 1 hour, 2 hours, 4 hours and 8 hours shown in Table 3.

\subsection{Result of the survey}

Fig. 2 shows how many commercial customers answered in each province in Korea.

In Table 4, the average commercial customer has 867.3 [kW] of contract power, 65.1 employees with 190.4 of monthly work hours, and pays 13,190 thousand KRW for monthly tariff. KRW means Korean Won. Among the business type, wholesale trade and commission trade(Type 2) show the largest number of employees and biggest contract power and tariff accordingly.

As of the date of survey, average frequency of power outages within the recent 1 year (classified by outage types) to each type of commercial customers are shown in Table 5. Though there were a small number of miscellaneous disturbances such as voltage swell and sag, almost all customers experienced average 1.1 momentary power interruptions in a year.

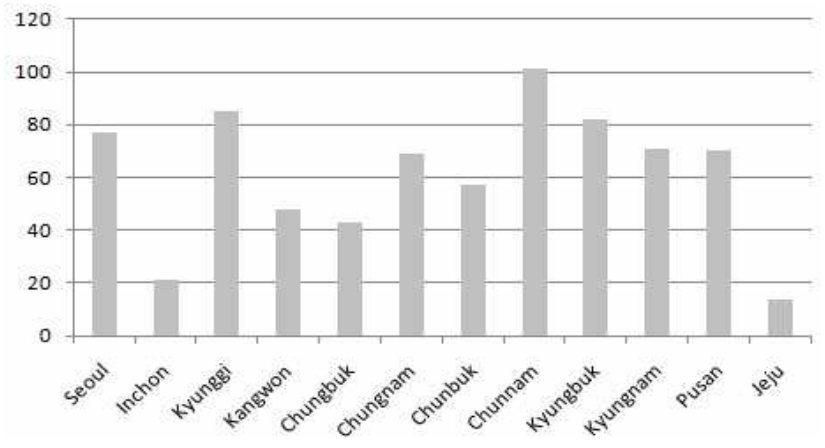

Fig. 2. Surveyed customers in each province 
Table 4. Average of survey factor on commercial customer

\begin{tabular}{c|c|c|c|c}
\hline Types & $\begin{array}{c}\text { Contract } \\
\text { power } \\
{[\mathrm{kW}]}\end{array}$ & $\begin{array}{c}\text { Avg. Number } \\
\text { of employees }\end{array}$ & $\begin{array}{c}\text { Avg. Monthly } \\
\text { work hours }\end{array}$ & $\begin{array}{c}\text { Avg. } \\
\text { Monthly tariff } \\
{[1,000 \mathrm{KRW}]}\end{array}$ \\
\hline All & 867.3 & 65.1 & 190.4 & $13,190.5$ \\
\hline 1 & 215.6 & 16.3 & 189.4 & $2,002.2$ \\
\hline 2 & $2,047.6$ & 145.6 & 189.0 & $35,932.3$ \\
\hline 3 & $1,132.2$ & 93.5 & 216.7 & $19,594.6$ \\
\hline 4 & 288.6 & 24.9 & 202.1 & $2,928.8$ \\
\hline 5 & 792.9 & 59.2 & 193.0 & $11,678.4$ \\
\hline 6 & 175.0 & 30.0 & 200.0 & 3797.4 \\
\hline 7 & 813.1 & 130.0 & 221.1 & $7,989.8$ \\
\hline 8 & $1,081.6$ & 37.0 & 208.1 & $14,964.8$ \\
\hline 9 & 73.6 & 7.4 & 173.7 & $1,027.5$ \\
\hline 10 & 222.9 & 10.4 & 146.4 & $3,107.2$ \\
\hline 11 & 784.1 & 58.4 & 192.1 & $11,554.0$ \\
\hline 12 & 737.5 & 120.8 & 182.5 & $9,768.0$ \\
\hline 13 & 922.5 & 104.5 & 181.5 & $17,583.8$ \\
\hline 14 & 56.3 & 21.3 & 242.5 & $1,226.0$ \\
\hline 15 & 869.2 & 62.9 & 192.0 & $13,112.6$ \\
\hline 16 & $1,290.4$ & 114.9 & 175.2 & $21,716.9$ \\
\hline 17 & 445.3 & 82.4 & 221.5 & $3,669.8$ \\
\hline 18 & $1,150.0$ & 46.7 & 213.8 & $8,254.1$ \\
\hline 19 & $1,692.7$ & 105.8 & 191.5 & $19,169.5$ \\
\hline 20 & 92.7 & 29.0 & 190.6 & 731.9 \\
\hline 21 & 291.2 & 12.4 & 197.3 & $3,600.1$ \\
\hline & & & &
\end{tabular}

Table 5. Frequency and class of power quality

\begin{tabular}{c|c|c|c|c|c|c|c}
\hline Types & Swell & $\begin{array}{c}\text { Over } \\
\text { voltage }\end{array}$ & Sag & $\begin{array}{c}\text { Under } \\
\text { voltage }\end{array}$ & Momentary Temporary & & \\
\hline All & 0.1 & 0.0 & 0.2 & 0.1 & 1.1 & 0.1 & 0.1 \\
\hline 1 & 0.1 & 0.1 & 0.4 & 0.1 & 1.1 & 0.2 & 0.4 \\
\hline 2 & 0.1 & 0.1 & 0.2 & 0.1 & 1.0 & 0.1 & 0.2 \\
\hline 3 & 0.0 & 0.0 & 0.2 & 0.1 & 1.0 & 0.1 & 0.1 \\
\hline 4 & 0.0 & 0.0 & 0.0 & 0.0 & 1.1 & 0.0 & 0.1 \\
\hline 5 & 0.1 & 0.0 & 0.2 & 0.1 & 1.1 & 0.1 & 0.1 \\
\hline 6 & 0.0 & 0.0 & 0.0 & 0.0 & 1.0 & 0.0 & 0.0 \\
\hline 7 & 0.2 & 0.1 & 0.4 & 0.2 & 0.8 & 0.1 & 0.1 \\
\hline 8 & 0.1 & 0.0 & 0.1 & 0.0 & 1.4 & 0.2 & 0.2 \\
\hline 9 & 0.0 & 0.0 & 0.1 & 0.0 & 0.8 & 0.1 & 0.1 \\
\hline 10 & 0.0 & 0.0 & 0.0 & 0.0 & 0.6 & 0.1 & 0.1 \\
\hline 11 & 0.1 & 0.0 & 0.2 & 0.1 & 1.1 & 0.1 & 0.1 \\
\hline 12 & 0.0 & 0.0 & 0.0 & 0.0 & 0.5 & 0.3 & 0.0 \\
\hline 13 & 0.4 & 0.0 & 0.5 & 0.0 & 0.7 & 0.1 & 0.0 \\
\hline 14 & 0.0 & 0.0 & 0.0 & 0.0 & 1.0 & 0.3 & 0.0 \\
\hline 15 & 0.1 & 0.0 & 0.2 & 0.1 & 1.0 & 0.1 & 0.1 \\
\hline 16 & 0.1 & 0.0 & 0.2 & 0.0 & 1.1 & 0.1 & 0.1 \\
\hline 17 & 0.0 & 0.0 & 0.1 & 0.0 & 1.3 & 0.0 & 0.0 \\
\hline 18 & 0.1 & 0.0 & 0.2 & 0.0 & 1.7 & 0.0 & 0.0 \\
\hline 19 & 0.1 & 0.0 & 0.6 & 0.2 & 1.2 & 0.1 & 0.1 \\
\hline 20 & 0.1 & 0.1 & 0.2 & 0.1 & 1.2 & 0.1 & 0.1 \\
\hline 21 & 0.1 & 0.0 & 0.5 & 0.1 & 1.2 & 0.0 & 0.1 \\
\hline
\end{tabular}

\section{Interruption Cost Results}

\subsection{Data selection}

To secure the high reliability of the result from the statistical analysis, inappropriate samples were removed. Among 738 data, those from 39 customers which had zero power consumption record in any month of the recent 1
Table 6. Excluded customer with no answers for interruption cost

\begin{tabular}{c|c|c|c|c|c|c}
\hline & $\begin{array}{c}1 \\
\text { min }\end{array}$ & $\begin{array}{c}20 \\
\text { min }\end{array}$ & $\begin{array}{c}1 \\
\text { hour }\end{array}$ & $\begin{array}{c}2 \\
\text { hours }\end{array}$ & $\begin{array}{c}4 \\
\text { hours }\end{array}$ & $\begin{array}{c}8 \\
\text { hours }\end{array}$ \\
\hline Excluded & 559 & 371 & 133 & 139 & 135 & 119 \\
\hline The rest & 140 & 328 & 566 & 560 & 564 & 580 \\
\hline
\end{tabular}

year were removed. Among the rest of 699 data, customers with no answers for power interruption costs were excluded and their tendency with power outage duration are shown in Table 6 . The longer the power outage duration was, the less the excluded data were. It is indirectly assumed that it is more difficult for customers to estimate their power interruption costs with shorter outage duration.

Data from customers have usually a big variance. This is because there exist huge differences among their power consumptions, business types, and expertise. To alleviate this deviation, Peak-normalized cost or the Consumptionnormalized cost is widely used to estimate the power interruption cost with which the total damage is divided by annual peak demand or annual power consumption [6]. In this paper, Peak-normalized cost calculation is adopted.

Peak-normalized cost

$$
=\frac{\text { cost }_{i}}{\text { peak }_{i}} \quad i=l, m[\mathrm{KRW} / \mathrm{kW}]
$$

$$
\begin{aligned}
& \text { Consumption-normalized cost } \\
& \qquad=\frac{\text { cost }_{i}}{\operatorname{cons}_{i}} \quad i=l, m[\mathrm{KRW} / \mathrm{kWh}]
\end{aligned}
$$

- i : each respondent

$-\mathrm{m}$ : the number of respondents for which both usable cost estimates and energy consumption values are available

- cost $_{\mathrm{i}}$ : the cost estimate in KRW

- peak $_{\mathrm{i}}$ : the annual peak demand in $\mathrm{kW}$

- cons $_{\mathrm{i}}$ : the annual consumption in $\mathrm{kWh}$

In the last step, customers with peak-normalized cost which surpassed 3 times of standard deviation value in positive or negative direction were removed. Like shown in Table 7, 2 6 data were removed from each time zone.

Table 7. Excluded customers for extreme values of costs

\begin{tabular}{c|c|c|c|c|c|c}
\hline & $\begin{array}{c}1 \\
\mathrm{~min}\end{array}$ & $\begin{array}{c}20 \\
\mathrm{~min}\end{array}$ & $\begin{array}{c}1 \\
\text { hour }\end{array}$ & $\begin{array}{c}2 \\
\text { hours }\end{array}$ & $\begin{array}{c}4 \\
\text { hours }\end{array}$ & $\begin{array}{c}8 \\
\text { hours }\end{array}$ \\
\hline Excluded & 2 & 2 & 6 & 5 & 5 & 5 \\
\hline The rest & 138 & 326 & 560 & 555 & 559 & 575 \\
\hline
\end{tabular}

\subsection{Estimation of power interruption cost}

Like before, Fig. 3 shows there still are huge differences among answers from customers even with the exclusion of 


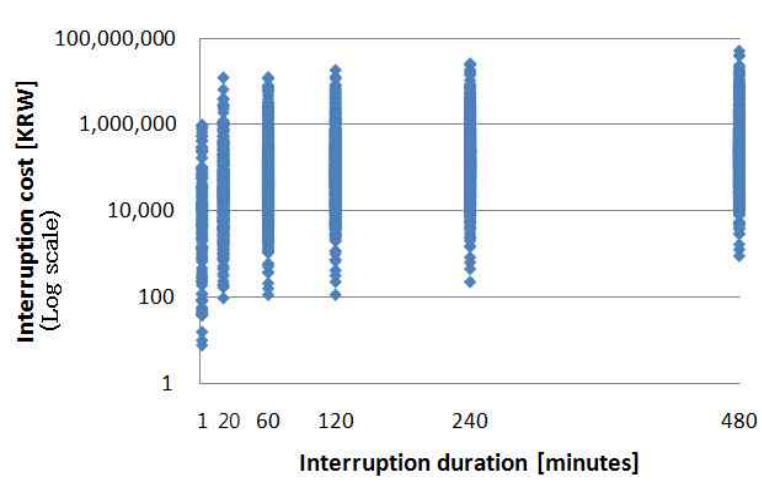

Fig. 3. Interruption costs with interruption duration

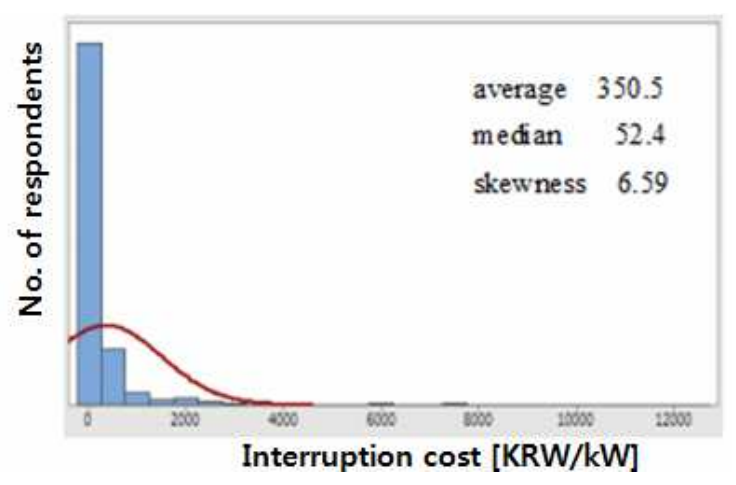

Fig. 4. Interruption cost distribution (with 1 hour of interruption duration)

wrong data. It shows $0.146(\mathrm{p}<.001)$ of Pearson coefficient between power outage duration and power interruption cost which is very low and means it is difficult to find the right function for these two variables. So a technique for descriptive statistics was adopted in this paper to calculate the power interruption cost rather than one for inferential statistics.

Fig. 4 shows the distribution of interruption cost when the interruption duration is 1 hour. It shows the typical pattern of positively skewed distribution with 6.59 of skewness and big difference between average and median values. In this case, the median is chosen for the representative value usually [7].

Table 8 shows the power interruption cost for each commercial customer type using median values. In case of less than 3 customers in a type, the representative value was not chosen. In certain types, the power interruption cost for 1 minute or 20 minutes were bigger than those of $1 \sim 8$ hours because more of 1 minute and 20 minutes data were removed in the process of wrong data exclusion.

Fig. 5 shows the customer damage functions for types of commercial customers. The biggest ones are that for Type 14(Computer programming, consultancy and related activities) and type 10(Publishing activities).

\subsection{Comparison with foreign countries}

Fig. 6 shows the trend of the power interruption cost of
Table 8. Interruption costs for business types $[1,000 \mathrm{KRW} /$ $\mathrm{kW}]$

\begin{tabular}{c|c|c|c|c|c|c}
\hline Types & $\begin{array}{c}1 \\
\text { min }\end{array}$ & $\begin{array}{c}20 \\
\text { min }\end{array}$ & $\begin{array}{c}1 \\
\text { hour }\end{array}$ & $\begin{array}{c}2 \\
\text { hours }\end{array}$ & $\begin{array}{c}4 \\
\text { hours }\end{array}$ & $\begin{array}{c}8 \\
\text { hours }\end{array}$ \\
\hline All & 9.1 & 25.9 & 52.4 & 80.5 & 129 & 219 \\
\hline 1 & 61 & 72 & 135 & 239 & 379 & 590 \\
\hline 2 & 2.2 & 8.7 & 31 & 61 & 120 & 215 \\
\hline 3 & 3.4 & 13 & 36.9 & 68 & 120 & 165 \\
\hline 4 & - & 32.6 & 46.9 & 50 & 53 & 62 \\
\hline 5 & - & - & - & - & - & - \\
\hline 6 & - & - & - & - & - & - \\
\hline 7 & 57.7 & 57 & 108 & 168 & 260 & 343 \\
\hline 8 & 19.1 & 23 & 33.8 & 36 & 64 & 82 \\
\hline 9 & 10.3 & 48.8 & 95 & 179.6 & 261.8 & 364 \\
\hline 10 & - & 357 & 170 & 427 & 538 & 704 \\
\hline 11 & - & - & - & - & - & 315 \\
\hline 12 & 1.4 & 3.7 & 7.9 & 15.8 & 31.5 & 63 \\
\hline 13 & 204 & 241 & 60 & 63 & 87 & 164 \\
\hline 14 & - & 111 & 344 & 714 & 783 & 891 \\
\hline 15 & - & - & - & - & - & - \\
\hline 16 & 6.5 & 17 & 38 & 63 & 101 & 180 \\
\hline 17 & 5.5 & 11.6 & 31.5 & 47 & 108 & 163 \\
\hline 18 & - & 92.2 & 25 & 58 & 77 & 154 \\
\hline 19 & 32.2 & 24 & 44.9 & 55 & 91 & 135 \\
\hline 20 & - & 93.7 & 128 & 185 & 228 & 420 \\
\hline 21 & 4.4 & 18.3 & 32.8 & 61.9 & 109 & 209 \\
\hline
\end{tabular}

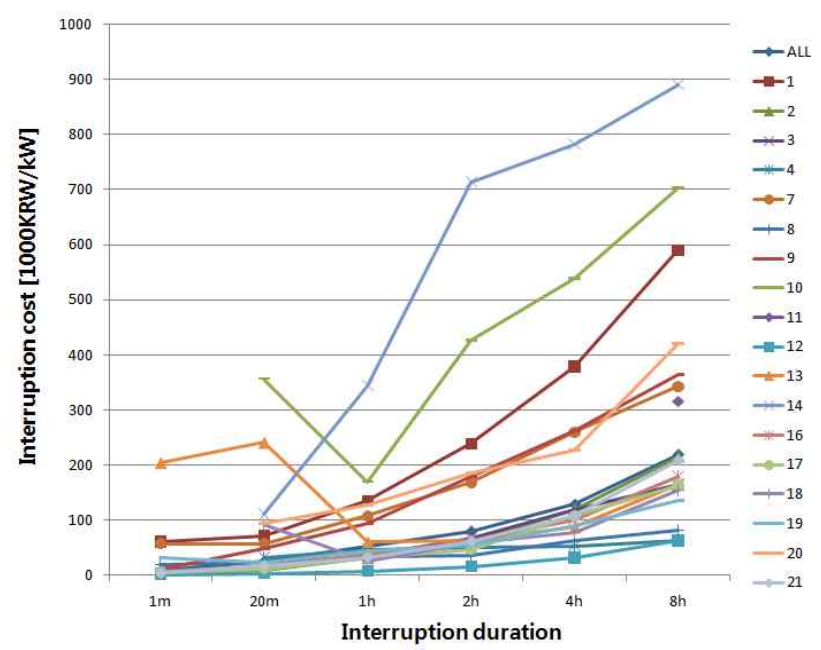

Fig. 5. Customer damage functions for business types

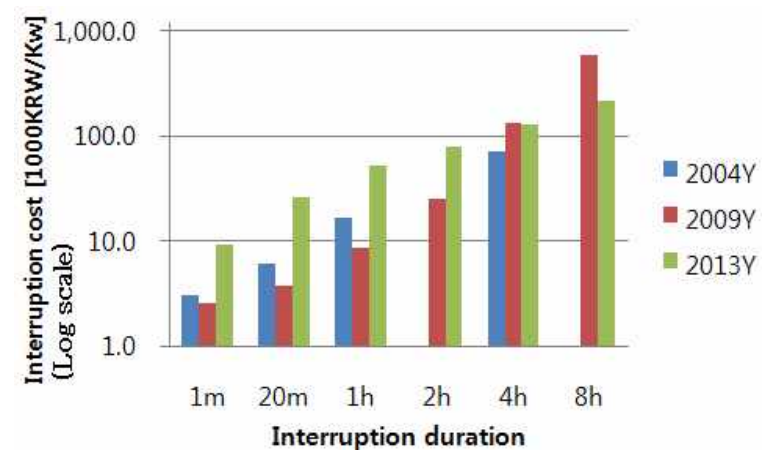

Fig. 6. Trend of power interruption cost for Korean commercial customers 
Table 9. Comparison with foreign countries [\$/kW]

\begin{tabular}{c|c|c|c|c|c|c|c}
\hline & $\begin{array}{c}1 \\
\text { min }\end{array}$ & $\begin{array}{c}20 \\
\text { min }\end{array}$ & $\begin{array}{c}1 \\
\text { hour }\end{array}$ & $\begin{array}{c}2 \\
\text { hours }\end{array}$ & $\begin{array}{c}4 \\
\text { hours }\end{array}$ & $\begin{array}{c}8 \\
\text { hours }\end{array}$ \\
\hline \multicolumn{2}{c|}{ NORWAY('03) } & 5.5 & 14.3 & 32.2 & 57.9 & 106.6 & 192.4 \\
\hline \multirow{2}{*}{$\begin{array}{c}\text { U.S } \\
\text { ('09) }\end{array}$} & S C\&I & - & 31.9 & 15.9 & - & 217.5 & 582.2 \\
\cline { 2 - 8 } & ML C\&I & - & 4.7 & 7.7 & 15.7 & 39.8 & 69.9 \\
\hline \multirow{2}{*}{$\begin{array}{c}\text { PG\&E } \\
\text { ('12) }\end{array}$} & SMB & - & - & 205.2 & - & 540.1 & $1,136.4$ \\
\cline { 2 - 8 } & LB & - & - & 327.4 & - & 436.9 & 449.7 \\
\hline \multicolumn{2}{l}{ KOREA('13) } & 8.3 & 23.8 & 48.1 & 73.8 & 118.7 & 200.6 \\
\hline
\end{tabular}

Korean commercial customers [8, 9]. Briefly, compared to the past, the power interruption cost with up to 2 hours of interruption increased steeply. With the 4 hours and 8 hours of power interruptions, it was similar or a little decreased. This may come from the differences of used methods or show commercial customers are more sensitive to short power outages.

Based on the researches done in the 21 st century, a comparison with foreign cases was done. Table 9 shows the power interruption costs of Norway, U.S, PG\&E(Power utility) and Korea [10-12]. With U.S data, commercial and industrial customers were aggregated and classified by small and medium/large size customers. With PG\&E, they were classified as medium/small and large commercial customers. $[\$ / \mathrm{kW}]$ was the unit for the cost and the recent exchange rate was applied. $(1 \$=6.25 \mathrm{NOK}=1,090 \mathrm{KRW})$

In Table 9, Norway and PG\&E used the average value, the U.S and Korea used the median value. In comparison with the U.S which is the same area, the power interruption cost of PG\&E using the average value is higher than that of U.S. It is assumed to be effected by positively skewed distribution according to previous Fig. 4. Compared to Norway which used the average value, the power interruption cost of PG\&E customers is about 5 times higher. Also, compared between the U.S and Korea which used the same median value, the power interruption cost of Korea is higher than the medium and large commercial/ industrial customers of the U.S, lower against the small commercial/industrial customers. In conclusion, the power interruption cost depends on the how to analysis the data, the additional research is required to get a meaningful result in the statistics.

\section{Conclusion}

The power interruption cost for Korean commercial customers was estimated through a survey. The survey was done evenly in every region of Korea and wrong data were removed to secure the reliability of the result of the statistical analysis. Commercial customers were classified in 21 business types according to KSIC and median values were used in the technical calculation of the power interruption costs reflecting characteristics of surveyed data. The power interruption cost in the 21 st century has a tendency to increase until 2 hours of power interruption duration in Korea. Also it is compared to that of Norway and U.S.

In the future, KEPCO will standardize the estimation method of power interruption cost which can reflect the characteristics of surveyed data and manage the information of power interruption cost with its own power interruption information system to estimate the related social costs.

\section{References}

[1] M. J. Sullivan, T. Vardell, and A. Vojadni, "Interruption Costs, Customer Satisfaction and Expectations for Service Reliability", IEEE Trans. Power Systems, vol. 11, no. 2, pp. 989-995, May 1996.

[2] M. Munasinghe, M. Gellerson, "Economic criteria for optimizing power systems reliability levels", Bell J. Econ., pp. 353-365, Spring 1979.

[3] Ponemon Institute, "2013 Cost of Data Center Outages", Dec. 2013.

[4] G. Wacker, R. Billinton, "Customer cost of electric service interruptions", IEEE Proc, vol. 77, Issue. 6, pp. 919-930, Jun. 1989.

[5] EPRI, “Outage Cost Estimation Guidebook”, EPRI TR-106082, Dec. 1995.

[6] R. Ghajar, R. Billinton, E. Chan, "Distributed nature of residential customer outage costs", IEEE Trans. Power Systems, vol. 11, no. 3, pp. 1236-1244, Aug. 1996.

[7] D. J. Sheskin, "Handbook of Parametric and Nonparametric Statistical Procedures: 3rd Edition”, CRC Press, Feb. 2013.

[8] KERI, "A Technology to Evaluate Reliability and Economy of Distribution Power System under Competition Structure", pp. 79-212, Aug. 2004.

[9] Y. H. Kim, "Evaluation of the Microscopic Customer Interrupt Cost of Commerce", KIEE Summer Conference, pp.196-197, 2010.

[10] M. J. Sullivan, M. Mercurio, J. Schellenberg, "Estimated Value of Service Reliability for Electric Utility Customers in the United States", LBNL-2132E, Jun. 2009.

[11] M. Sullivan, M. Perry, "Pacific Gas \& Electric Company's 2012 Value of Service Study”, May 2012

[12] Gerd H. Kjølle, Knut Samdal, etc, "Customer Costs Related to Interruptions and Voltage Problems: Methodology and Results", IEEE Trans. Power Systems, vol. 23, no. 3, pp. 1030-1038, Aug. 2008 


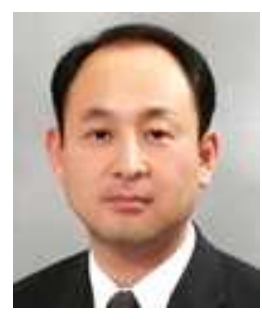

Dong-Sub Kim He received B.S and M.S degree in electrical engineering from Hanyang University, Seoul, Korea in 1982 and 2000 respectively. He is taking the doctorial course majoring in technology policy from Yonsei graduate school. He has been working on Korea Electric Power Corporation (KEPCO) since 1985 and now is positioning on a Director of Distribution Operation Department.

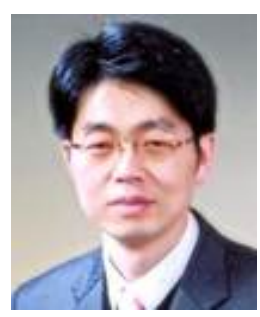

Kil-Sin Kim He received B.S and M.S degree in electrical engineering from Hanyang University, Seoul, Korea in 1993 and 1998 respectively. $\mathrm{He}$ is currently a senior researcher in Korea Electric Power Research Institute (KEPRI). His research interests include the distribution system operation, environmental reliability test. 